\title{
Multiple Pathologies in the Kidney Biopsy of a Recently Pregnant Woman
}

\author{
Kiran Kandukurti ${ }^{\mathrm{a}}$ Jianlan Sun ${ }^{\mathrm{b}}$ Rocco Venuto ${ }^{\mathrm{a}}$ \\ ${ }^{a}$ Division of Nephrology, Department of Internal Medicine, and ${ }^{b}$ Department of \\ Pathology, State University of New York, Buffalo, N.Y., USA
}

\section{Key Words}

Hypertension · Preeclampsia - Acute tubular necrosis - Focal segmental glomerulosclerosis

\begin{abstract}
We report a 42-year-old woman with underlying hypertension, mild renal dysfunction and proteinuria who presented as an obstetric emergency with uncontrolled hypertension and nephrotic syndrome. The rapid deterioration in her kidney function and worsening of her symptoms led to an urgent termination of her twin pregnancy. Although a clinical improvement was noticed within 10 days, the persistently elevated serum creatinine required further evaluation. A kidney biopsy showed changes consistent with acute tubular necrosis and resolving preeclampsia superimposed on focal segmental glomerulosclerosis and hypertensive kidney disease. The importance of a kidney biopsy in confirming clinical suspicions and determining patient prognosis is emphasized.
\end{abstract}

\section{Introduction}

We present a female patient with suspected but unconfirmed focal segmental glomerulosclerosis (FSGS) who developed preeclampsia and rapidly progressive renal dysfunction. A kidney biopsy was undertaken to determine the cause of the severe acute kidney injury and the prolonged period of recovery of her renal function. The value of the pathology findings in clarifying the diagnosis and guiding patient management are reviewed. 


\section{Case Presentation}

A 42-year-old, 24 weeks pregnant $\left(\mathrm{G}_{2} \mathrm{P}_{0}\right)$ African American woman with a history of hypertension, elective medical termination of pregnancy (December 2009) and residual right hand tremor related to cervical and lumbar spine injury following a motor vehicle accident was admitted to a local maternity hospital in February 2011 with uncontrolled hypertension, shortness of breath and anasarca. She was not on any antihypertensive medication as she did not wish to take any. The patient was on furosemide $20 \mathrm{mg}$ once daily for 2 months of progressive dyspnea on exertion and 1 month of increasing pedal edema when she was informed that she was 22 weeks pregnant with twins. Whilst awaiting an antenatal clinic appointment, her shortness of breath and swelling rapidly worsened, leading to an urgent admission to the intensive care unit. On examination, the patient was tachypneic and afebrile. Her blood pressure was $177 / 134 \mathrm{~mm} \mathrm{Hg}$, the heart rate was $108 / \mathrm{min}$ and the respiratory rate was $38 / \mathrm{min}$. A grade $2 / 6$ systolic murmur was audible throughout the precordium, decreased air entry was noted at both lung bases and there was generalized anasarca. Her hypertension was initially treated with intravenous labetalol and oral diltiazem. An echocardiogram showed an ejection fraction of $45-50 \%$ with mild concentric left ventricular hypertrophy and mild-to-moderate mitral regurgitation. An ultrasound of the kidneys showed a hyperechoic pattern consistent with medical renal disease. Over the next 3 days, her blood pressures remained elevated at 153-166/84-119 mm Hg, kidney function deteriorated and proteinuria worsened. A medical termination of pregnancy was performed using a laminaria stick followed by misoprostol a day later. The placenta showed multiple infarcts without any pathologic change in the membranes. The patient was then transferred to a tertiary care hospital nephrology unit.

On arrival to the medicine floor, her blood pressure was $153 / 114 \mathrm{~mm} \mathrm{Hg}$. The patient responded to aggressive diuresis with a weight loss of $20.5 \mathrm{~kg}$ and improvement in her symptoms. However, her serum creatinine, blood pressure and urine random protein/creatinine ratio all remained high (4.1-4.5 mg/dl [362.44-397.8 $\mu \mathrm{mol} / \mathrm{l}], 160 / 103 \mathrm{~mm}$ $\mathrm{Hg}$ and $10.16 \mathrm{mg} / \mathrm{mg}$, respectively). A kidney biopsy was deemed necessary to explain the kidney failure (fig. 1a-f). Table 1 outlines the relevant laboratory investigations that were performed before the kidney biopsy. A careful review of the patient's previous case records showed a low estimated glomerular filtration rate of $72-80 \mathrm{ml} / \mathrm{min} / 1.73 \mathrm{~m}^{2}$ $\left(1.20024-1.3336 \mathrm{ml} / \mathrm{s} / 1.73 \mathrm{~m}^{2}\right)$, an elevated creatinine level of $1.0-1.1 \mathrm{mg} / \mathrm{dl}(88.4-97.24$ $\mu \mathrm{mol} / \mathrm{l}$ ) and $2+$ protein in a qualitative urinalysis in 2006. Unfortunately, an acute right pontine stroke prolonged her hospital stay. Tests for antiphospholipid antibody syndrome and systemic lupus erythematosus were negative. She was discharged home from the acute stroke rehabilitation unit following improvement in her symptoms.

The patient was reexamined 15 days later in the nephrology clinic. Multiple blood pressure measurements ranged from 128-130/82-83 mm Hg. Her lung fields were clear, heart auscultation showed absence of the systolic murmur and there was trace of pedal edema. The serum creatinine level improved from $2.4 \mathrm{mg} / \mathrm{dl}(212.16 \mu \mathrm{mol} / \mathrm{l})$ to $2.1 \mathrm{mg} / \mathrm{dl}(185.64$ $\mu \mathrm{mol} / \mathrm{l}$ (fig. 2). The urine protein/creatinine ratio had improved from $10.16 \mathrm{mg} / \mathrm{mg}$ to 5.57 $\mathrm{mg} / \mathrm{mg}$ (fig. 3). The patient is currently on lisinopril for hypertension and proteinuria.

Light microscopic examination showed a core biopsy of renal parenchyma containing ten glomeruli; five were globally sclerosed, and three showed mesangial increase, prominent foam cells and evidence of early sclerosis. The remaining two glomeruli had segmental sclerosis, with one showing adhesions to Bowman's capsule (fig. 1a). One of the glomeruli showed swelling of the capillary endothelial cells with narrowed lumen (endotheliosis) and mild vacuolation in the endothelial cytoplasm (fig. 1b). The interlobular arteries showed 
thickening of their wall with subintimal fibrosis, which reduced the lumen by up to $50 \%$ (fig. 1c). There was moderate tubular atrophy, associated interstitial fibrosis and a patchy mild interstitial inflammatory infiltrate composed of lymphoplasmacytic cells, eosinophils and occasional neutrophils. Many tubules showed loss of tubular lining cells with occasional mitotic figures (fig. 1d). Immunofluorescence microscopy showed weak staining for IgM $(+/-)$, and moderately strong mesangial staining for C3 $(2 \sim 3+)$. IgA, IgG and fibrinogen stains were negative (fig. 1f). Electron microscopy revealed extensive fusion of the podocyte foot processes and associated villous transformation (fig. 1e). Ischemic collapse, thickening of the peripheral loops and an increase in the mesangial matrix and cells were noted. The basement membrane thickness was $413 \mathrm{~nm}$ on average. The examined tubular and vascular compartments confirmed the impression on light microscopy. The kidney biopsy showed changes consistent with resolving preeclampsia superimposed on a background of FSGS, acute tubular necrosis (ATN), mild tubulointerstitial nephritis and moderate-to-severe arterial sclerosis in the large arteries.

\section{Discussion}

Preeclampsia is the most common cause of nephrotic range proteinuria in pregnant women [1]. Superimposed preeclampsia in a patient with chronic hypertension includes worsening of hypertension, development of new onset proteinuria with symptoms suggestive of other organ damage, i.e. headache, visual changes, upper abdominal pain or elevated liver enzymes, low platelet count and hemolysis (HELLP) syndrome [2]. Our patient had multiple risk factors, which favored the development of preeclampsia. These included underlying proteinuric renal disease, untreated hypertension, nulliparity, twin pregnancy, older maternal age and thrombotic vascular disease [3]. One of the glomeruli (fig. 1b) showed glomerular capillary endotheliosis, a transient pathological finding often seen in patients with preeclamptic nephropathy [4]. These changes are currently deemed a consequence of widespread endothelial dysfunction [5]. Endothelial dysfunction in preeclampsia has been speculated to result from increased levels of a soluble fms-like tyrosine kinase 1, which antagonizes the effects of vascular endothelial growth factor and placental growth factor [6]. The rise in the patient's serum albumin and the decline in her urine protein/creatinine ratio within 2 months following the termination of pregnancy are typical for the resolution of proteinuria in preeclampsia.

The signs of preeclampsia characteristically occur during the last trimester of pregnancy. The early onset of her symptoms around 20 weeks was suggestive of an undiagnosed primary renal pathology such as FSGS, a common cause of nephrotic range proteinuria and hypertension in African American adults [7]. Studies suggest that the high frequency of gene variations in genes such as the $\mathrm{MYH}-9$ gene in this ethnic group puts them at a greater risk of developing idiopathic FSGS and hypertension-related kidney disease [8]. A qualitative urinalysis undertaken nearly 5 years earlier revealed $2+$ protein. Pathological changes as seen in FSGS were observed (fig. 1a, e, f) which supported our strong suspicion of the underlying pathology. The clinical diagnosis of hypertension had been made just the year before proteinuria was detected. The distinctive effects of chronic hypertension including intimal fibrosis and arterial wall thickening (fig. 1c), however, suggested its presence for many years prior to the diagnosis. These changes undoubtedly contributed to the patient's renal dysfunction.

ATN and rapid progression of FSGS were both considered in an attempt to explain the sudden rise in serum creatinine (fig. 2). ATN is an uncommon but not a rare complication of 
severe preeclampsia [9]. Thinning of the tubular epithelium with occasional mitotic figures (fig. 1d) confirmed that the acute kidney injury was due to ATN. The progressive decline in serum creatinine, which was noted over a period of 6-8 weeks, is consistent with the concomitant recovery from the direct kidney injury of ATN and preeclampsia.

In conclusion, the quadruple pathology of ATN, superimposed preeclampsia, FSGS and chronic hypertension in this single kidney biopsy were distinctly uncommon findings. The timing of the biopsy was crucial since changes of glomerular capillary endotheliosis and ATN tend to disappear within a few weeks or lessen following the primary insult. These findings reinforced the clinical notion that there was a reversible injury either as a direct or as an indirect consequence of the patient's pregnancy and helped define prognosis.

\section{Disclosure Statement}

The authors declare that they have no relevant financial interests.

\section{References}

-1 Fisher KA, Ahuja S, Luger A, Spargo BH, Lindheimer MD: Nephrotic proteinuria with pre-eclampsia. Am J Obstet Gynecol 1977;129:643-646.

-2 Tuuli MG, Rampersad R, Stamilio D, Macones G, Odibo AO: Perinatal outcomes in women with preeclampsia and superimposed preeclampsia: do they differ? Am J Obstet Gynecol 2011;204:508 e1-e7.

-3 Karumanchi SA, Maynard SE, Stillman IE, Epstein FH, Sukhatme VP: Preeclampsia: a renal perspective. Kidney Int 2005;67:2101-2113.

-4 Spargo B, McCartney CP, Winemiller R: Glomerular capillary endotheliosis in toxemia of pregnancy. Arch Pathol 1959;68:593-599.

5 Stillman IE, Karumanchi SA: The glomerular injury of preeclampsia. J Am Soc Nephrol 2007;18:2281-2284.

-6 Maynard SE, Min JY, Merchan J, Lim KH, Li J, Mondal S, Libermann TA, Morgan JP, Sellke FW, Stillman IE, Epstein FH, Sukhatme VP, Karumanchi SA: Excess placental soluble fms-like tyrosine kinase 1 (sFlt1) may contribute to endothelial dysfunction, hypertension, and proteinuria in preeclampsia. J Clin Invest 2003;111:649-658.

7 Tucker JK: Focal segmental glomerulosclerosis in African Americans. Am J Med Sci 2002;323:90-93.

-8 Singh N, Nainani N, Arora P, Venuto RC: CKD in MYH9-related disorders. Am J Kidney Dis 2009;54:732-740.

9 Sibai BM, Villar MA, Mabie BC: Acute renal failure in hypertensive disorders of pregnancy. Pregnancy outcome and remote prognosis in thirty-one consecutive cases. Am J Obstet Gynecol 1990;162:777-783. 
Table 1. Relevant laboratory investigations before the kidney biopsy

\begin{tabular}{ll}
\hline Parameter & Value \\
\hline Qualitative urinalysis & Sp.gr 1.020, 3+ protein, 3+ blood \\
Urine total protein, $\mathrm{mg} / \mathrm{day}$ & 11,610 \\
Platelet count, $\times 10^{9} / \mathrm{l}$ & 192 \\
Serum uric acid, $\mathrm{mg} / \mathrm{dl}$ & 7.4 \\
ALT, U/l & 15 \\
AST, U/l & 24 \\
ALP, U/l & 105 \\
Total bilirubin, mg/dl & 0.8 \\
Serum albumin, g/dl & 0.9 \\
Lipid profile, mg/dl & TC 449; LDL-C 291; HDL-C 62; TG 848 \\
C3, g/l & 2.33 \\
C4, g/l & 0.45 \\
ANA, ANCA, anti GBM, anti ds DNA antibodies & Negative \\
Urine electrophoresis & Whole IgG and IgA detected \\
Urine for free light chains & Interference with free light chain determination \\
& noted due to whole immunoglobulins \\
\hline
\end{tabular}

Conversion factors for units: uric acid in $\mathrm{mg} / \mathrm{dl}$ to $\mu \mathrm{mol} / \mathrm{l}, \times 59.48$; total bilirubin in $\mathrm{mg} / \mathrm{dl}$ to $\mu \mathrm{mol} / \mathrm{l}, \times 17.1$; albumin in $\mathrm{g} / \mathrm{dl}$ to $\mathrm{g} / \mathrm{l}, \times 10$; total serum cholesterol in $\mathrm{mg} / \mathrm{dl}$ to $\mathrm{mmol} / \mathrm{l}, \times 0.02586$; low-density lipoprotein cholesterol in $\mathrm{mg} / \mathrm{dl}$ to $\mathrm{mmol} / \mathrm{l} \times 0.02586$; high-density lipoprotein cholesterol in $\mathrm{mg} / \mathrm{dl}$ to $\mathrm{mmol} / \mathrm{l}$, $\times 0.02586$; triglycerides in $\mathrm{mg} / \mathrm{dl}$ to $\mathrm{mmol} / \mathrm{l}, \times 0.01129$; no conversion necessary for platelets in $\times 10^{9} / \mathrm{l}$ and $\times 10^{3} / \mu \mathrm{l}$. Sp.gr = Specific gravity; ALT = alanine aminotransferase; AST = aspartate aminotransferase; ALP = alkaline phosphatase; TC = total cholesterol; LDL-C = low-density lipoprotein cholesterol; HDL-C = highdensity lipoprotein cholesterol; TG = triglycerides; C3 and C4 = complements 3 and 4; ANA = antinuclear antibody; ANCA = antineutrophil cytoplasmic antibody; GBM = glomerular basement membrane; ds DNA = double-stranded DNA; Ig = immunoglobulin. 


\section{Case Reports in \\ Nephrology and Urology}

Case Rep Nephrol Urol 2013;3:9-15 DOI: $\underline{10.1159 / 000346862}$

Kandukurti et al.: Multiple Pathologies in the Kidney Biopsy of a Recently Pregnant Woman
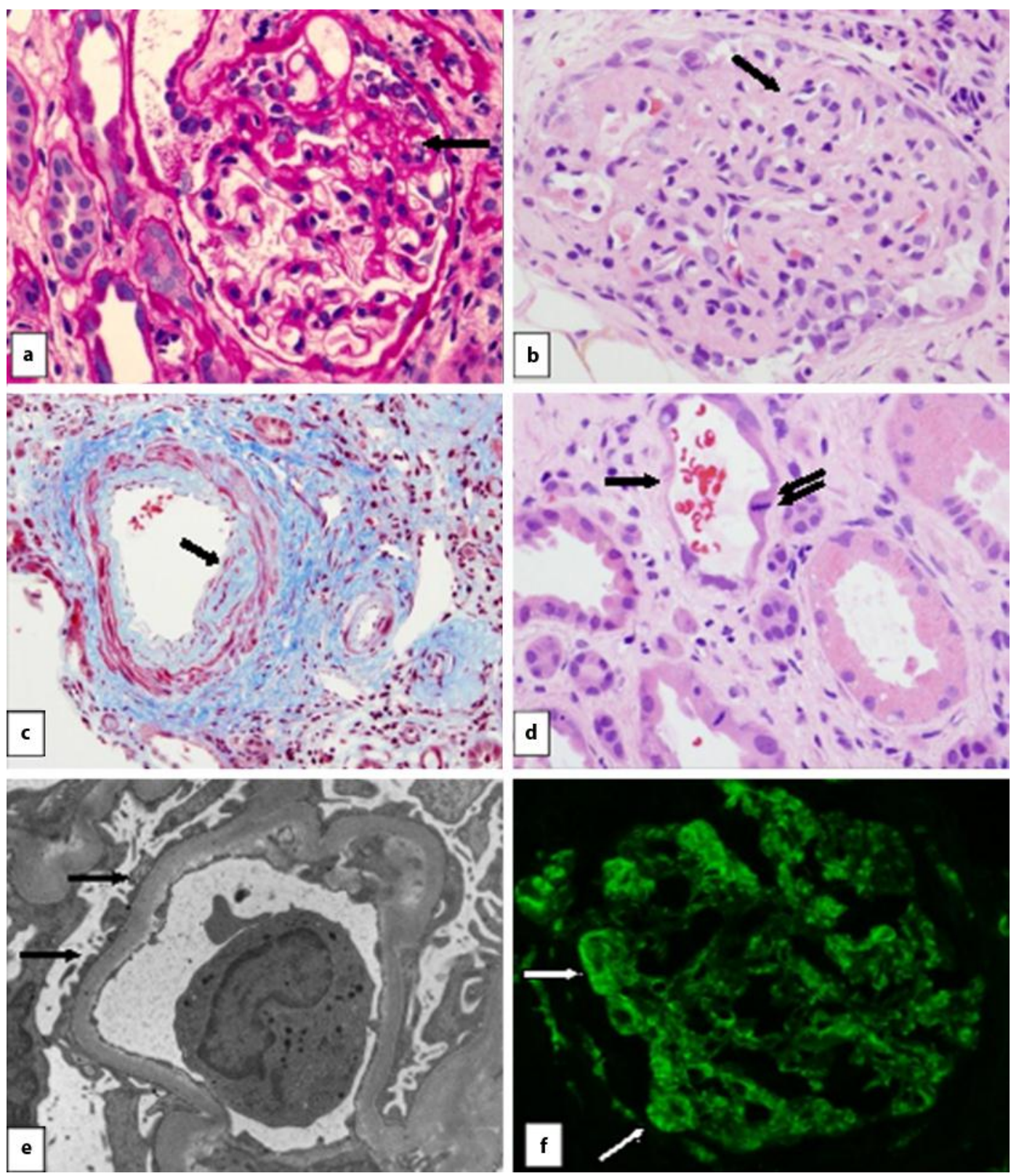

Fig. 1. Multiple pathologies in a single kidney biopsy. a Segmental sclerosis in a glomerulus. An increased paucicellular matrix, hyalinosis, endocapillary foam cells and wrinkled basement membrane (single arrow) are shown. Periodic acid-Schiff stain. $\times 200$. b Superimposed preeclampsia. The glomerulus shows a 'bloodless' appearance with a swelling of the capillary endothelial cells and occluded or narrowed lumens, i.e. endotheliosis (single arrow). Mild vacuolation is noted in some endothelial cytoplasm. Hematoxylin and eosin stain. $\times 400$. c Hypertension. The interlobular artery shows thickening of the wall with subintimal fibrosis, consistent with hypertensive disease (single arrow). Gomori trichrome stain. $\times 400$. $d$ Acute tubular necrosis. There is thinning of the tubular epithelium (single arrow) with loss of the nuclei, suggesting coagulative necrosis, and occasional mitotic figures (double arrows) can be seen. Hematoxylin and eosin stain. $\times 400$. e Focal segmental glomerulosclerosis. A marked foot process effacement in a non-sclerotic capillary loop without electron-dense deposits (single arrows). Electron micrograph. f Focal segmental glomerulosclerosis. Granular staining of C3 is noted in the glomerulus (single arrows). Immunoflourescence. $\times 400$. 


\section{Case Reports in \\ Nephrology and \\ Urology}

\begin{tabular}{l|l}
\hline Case Rep Nephrol Urol 2013;3:9-15 & \\
\hline DOI: $\underline{10.1159 / 000346862}$ & $\begin{array}{l}\text { @ 2013 S. Karger AG, Basel } \\
\text { www.karger.com/cru }\end{array}$ \\
\hline
\end{tabular}

Kandukurti et al:: Multiple Pathologies in the Kidney Biopsy of a Recently Pregnant Woman

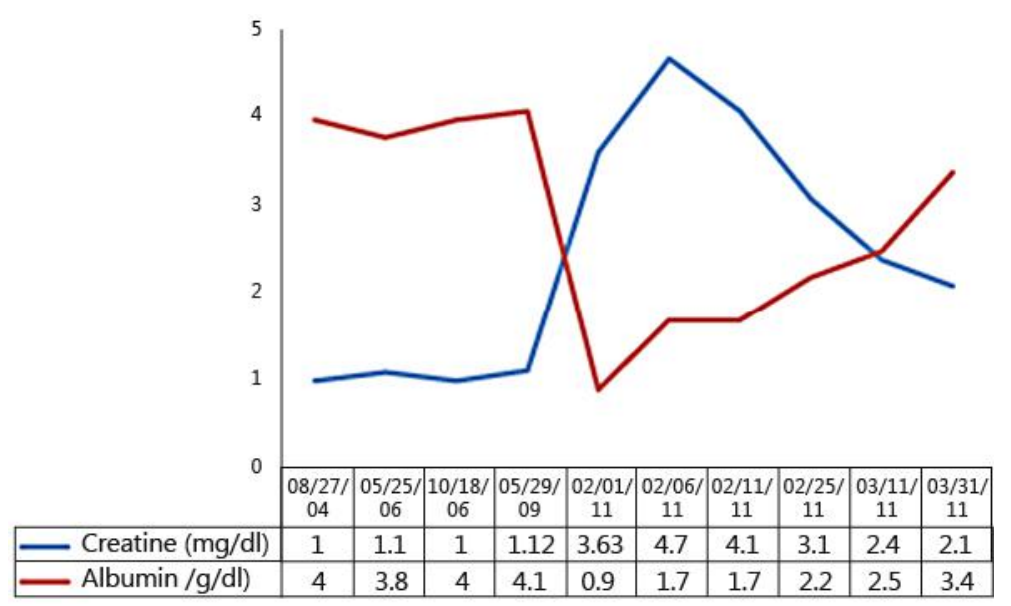

Fig. 2. Trends in serum creatinine and serum albumin levels over a period of approximately 6.5 years (August 2004-March 2011).

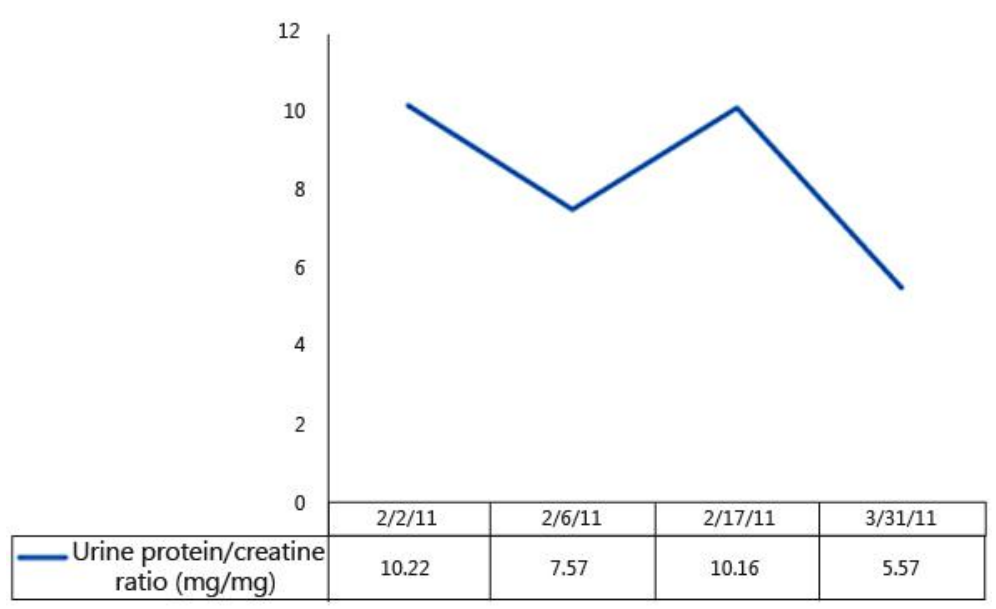

Fig. 3. Trends in urine random protein/creatinine ratio over a period of 2 months (February-March 2011). 